\title{
AMELIORATION OF MICROVASCULAR MYOCARDIAL ISCHEMIA BY GENE TRANSFER OF VASCULAR ENDOTHELIAL GROWTH FACTOR IN RABBITS
}

Etsuro Tanaka, MD, $\mathrm{PhD}^{\mathrm{a}, \mathrm{d}}$

Naoichiro Hattan, MD a,d

Kiyoshi Ando, $\mathrm{MD}, \mathrm{PhD}^{\mathrm{b}, \mathrm{d}}$

Hikaru Ueno, $\mathrm{MD}, \mathrm{PhD}^{\mathrm{e}}$

Yoshinori Sugio, $\mathrm{MD}^{\mathrm{c}}$

Minhaz U. Mohammed, MD, PhD

Svetlana A. Voltchikhina, $\mathrm{PhD}^{\mathrm{a}}$

Hidezo Mori, MD, $\mathrm{PhD}^{\mathrm{a}, \mathrm{d}}$
Objectives: Restoration of coronary blood flow by angiogenesis may offer a new approach to intractable ischemic heart disease. In the present study, we investigated the angiogenic effects of gene transfer of vascular endothelial growth factor 165 on microvascular myocardial ischemia.

Methods: A rabbit model of microvascular myocardial ischemia was created by plugging coronary microvessels with microspheres $(15 \mu \mathrm{m}$ in diameter, $2.8 \times 10^{5} / \mathrm{kg}, \mathrm{n}=29$ ). Gene transfer was performed by semi-selective intracoronary injection of recombinant adenovirus expressing vascular endothelial growth factor 165 forty minutes after microsphere injection $(n=9)$.

Results: Microsphere injection reduced myocardial perfusion $(78 \% \pm 9 \%$ of baseline tissue flow) and diminished myocardial contraction $(61 \% \pm 12 \%$ of the baseline ejection fraction) and cardiac performance (elevated left ventricular end-diastolic pressure and decreased systemic flow) in the acute phase. At $17 \pm 3$ days, gene transfer of vascular endothelial growth factor 165 had had the following effects: (1) promoted coronary angiogenesis as evidenced by myocardial flow above the baseline $(121 \% \pm 24 \%)$, (2) increased vascular density revealed by synchrotron radiation microangiography and histologic analysis, (3) ameliorated the degree of myocardial ischemia as evidenced by myocardial lactate content and the extent of histologic necrosis, and (4) restored heart function as evidenced by increased ejection fraction $(95 \% \pm 10 \%)$, reduced left ventricular end-diastolic pressure, and restored body weight.

Conclusions: In vivo vascular endothelial growth factor 165 gene transfer promoted angiogenesis and was an effective approach to treating microvascular myocardial ischemia. (J Thorac Cardiovasc Surg 2000;120:720-8)
From the Departments of Physiology, ${ }^{\mathrm{a}}$ Internal Medicine, ${ }^{\mathrm{b}}$ and Surgery ${ }^{\mathrm{c}}$ and the Reserch Center for Genetic Engineering and Cell Transplantation, ${ }^{\mathrm{d}}$ Tokai University School of Medicine, Isehara, Japan; and the Department of Cardiology, ${ }^{\text {e }}$ Faculty of Medicine, Kyushu University, Fukuoka, Japan.

Supported by Grants-in-Aid for Scientific Research (09670756 and 10470171) from the Ministry of Education, Science, Sports and Culture of Japan; "Research for the Future" Program by The Japan Society for the Promotion of Science (JSPSRFTF97I00201); New Energy and Industrial Technology Development Organization; The Science Frontier Program of MESSC of Japan; Tokai University School of Medicine Project Research and Research Aid; and The Ichiro Kanehara Foundation.

Received for publication Dec 7, 1999; revisions requested Feb 18, 2000; revisions received May 25, 2000; accepted for publication June 14, 2000

Address for reprints: Hidezo Mori, MD, PhD, Department of Physiology, Tokai University School of Medicine, Isehara 2591193, Japan (E-mail: coronary@ keyaki.cc.u-tokai.ac.jp).

Copyright () 2000 by The American Association for Thoracic Surgery

$0022-5223 / 2000 \$ 12.00+0 \quad \mathbf{1 2 / 1 / 1 0 9 5 3 6}$

doi: $10.1067 / \mathrm{mtc} .2000 .109536$ /ascular endothelial growth factor (VEGF) is an endothelial cell-specific mitogen that promotes angiogenesis. ${ }^{1,2}$ Four different VEGF transcripts encoding polypeptides of 206, 189, 165, and 121 amino acids are expressed by human cells. Administration of VEGF $_{165}$ caused angiogenesis in ameroid-induced ischemia in canine ${ }^{3}$ and porcine ${ }^{4}$ hearts. Gene therapy has the potential to induce protein expression, and adenoviral vectors have provided high-yield gene transfers to the heart. ${ }^{5}$ Mack and associates ${ }^{6}$ demonstrated the usefulness of gene therapy for ameroid-induced cardiac ischemia by direct intramuscular administration of an adenovirus vector expressing $\mathrm{VEGF}_{121}$ in swine, and similar results have been reported for intracoronary gene transfer of fibroblast growth factor $5 .^{7}$ In the present study, we evaluated the effects of gene therapy in a model of microvascular ischemia. Microvascular myocardial ischemia is an example of intractable myocardial ischemia ${ }^{8}$ since neither percutaneous trans- 
luminal coronary angioplasty nor coronary artery bypass grafting can be used to treat small segments of the epicardial coronary arteries having a diameter of less than $1 \mathrm{~mm}$ or intramural coronary vessels. In this study, we created microvascular myocardial ischemia in rabbits by plugging coronary beds with $15 \mu \mathrm{m}$ microspheres. This model is characterized by sustained nonnecrotic myocardial ischemia lasting more than 2 months. ${ }^{9,10}$ We evaluated the effects of gene transfer by intracoronary injection of recombinant adenovirus expressing $\mathrm{VEGF}_{165}$ (Ad-VEGF) and lacZ (Ad-lacZ) on this microvascular ischemia model.

\section{Methods}

This investigation was carried out in conformity with the "Guide for the Care and Use of Laboratory Animals" published by the National Institutes of Health (NIH publication No. 86-23, revised 1985). All procedures were performed with the animals under general anesthesia, that is, after intravenous injection of sodium pentobarbital $(30 \mathrm{mg} / \mathrm{kg})$.

Experimental protocols. Forty-six Japanese White rabbits weighing $3.57 \pm 0.46 \mathrm{~kg}$ (Tokyo Laboratory Animal Science Co, Ltd, Tokyo, Japan) were used. In 39 of the rabbits, microvascular ischemia was created by injecting indiumlabeled microspheres having a diameter of $15 \mu \mathrm{m}$, and the remaining 7 rabbits were used to obtain normal standards for the metabolic or histologic indices. The ischemic rabbits $(\mathrm{n}=$ 39) were further divided into 3 groups as follows. After microsphere injection, the hearts of 18 rabbits were injected with saline solution (sham-1 group), the hearts of 8 rabbits were injected with $6 \times 10^{9}$ plaque-forming units (pfu) of Ad-lacZ (sham-2 group), and the hearts of the remaining 13 rabbits were injected with $6 \times 10^{9} \mathrm{pfu}$ of Ad-VEGF (VEGF group). Twentynine of the 39 ischemic rabbits were killed 14 to 21 days (mean, 17 days) after microsphere injection, and 10 rabbits were killed 4 days after the injection to confirm the delivered gene.

A $3 \mathrm{~F}$ catheter was placed in the right femoral artery to record aortic pressure and to obtain reference blood samples for measurement of regional blood flow during microsphere injection. The tip of a $4 \mathrm{~F}$ catheter was positioned in the left ventricle via the right common carotid artery to record left ventricular pressure and to inject microspheres and adenovirus. The tip of a $4 \mathrm{~F}$ Fogarty balloon catheter (Baxter Healthcare, Inc, Irvine, Calif) was positioned in the thoracic descending aorta via the left femoral artery to obstruct aortic blood flow by balloon inflation. During balloon inflation, we confirmed that femoral artery pressure was less than $20 \mathrm{~mm}$ $\mathrm{Hg}$. The injections of indium-labeled microspheres for coronary artery plugging and for virus solution were terminated within 40 seconds, but balloon inflation and temporary ligation of the left common carotid artery were maintained until 70 seconds after the start of the injection. Under these conditions, blood flow to the abdominal organs and lower extremities was substantially interrupted by balloon inflation, and blood flow to the head was interrupted by bilaterally occlud- ing the common carotid arteries (blood flow via the vertebral arteries was left intact). Comparison between the relative elemental activity ratio (heart/kidney) of barium-labeled microspheres for flow measurement $(0.72 \pm 0.33)$ and indiumlabeled microspheres for coronary plugging $(7.30 \pm 3.57)$ indicated high selectivity (approximately 10-fold difference) of our method for microvascular plugging and gene delivery in the heart.

The microspheres $(15 \mu \mathrm{m}$ in diameter) were labeled with one of four sets of stable heavy elements (indium, iodine, barium, or cerium; Sekisui Plastic, Osaka, Japan) ${ }^{11}$ and suspended in $0.05 \%$ sodium dodecyl sulfate at a concentration of $5.0 \times 10^{5} / \mathrm{mL}$. The indium-labeled microspheres $\left(2.8 \times 10^{5} / \mathrm{kg}\right)$ were gently injected into the left ventricle in 3 doses at 10-minute intervals to plug the coronary artery system of the heart. X-ray fluorescence of indium indicated the degree of plugging of arterioles having a diameter of $15 \mu \mathrm{m}$. There were no significant differences among the 3 groups: $178 \pm 88,169 \pm 68$, and $193 \pm 132$ counts $\cdot \mathrm{s}^{-1} \cdot \mathrm{g}^{-1}$ in the sham-1 $(\mathrm{n}=11)$, sham-2 $(\mathrm{n}=6)$, and VEGF groups $(n=6)$, respectively. In one series of preliminary experiments, administration of $5.0 \times 10^{5} / \mathrm{kg}$ indium-labeled microspheres to 2 rabbits resulted in the death of both within 2 days (100\%), and administration of $3.75 \times 10^{5} / \mathrm{kg}$ to 5 rabbits resulted in the death of 4 of them $(80 \%)$. Even injection of the dose used in this study $\left(2.8 \times 10^{5} / \mathrm{kg}\right)$ led to the death of 9 of the 54 rabbits (17\%) within 2 days. In the other series of preliminary experiments in rabbits, we detected diffuse extensive reduced nicotinamide adenine dinucleotide (NADH) fluorescence of myocardium at 16 days after the microsphere injection. NADH fluorescence is from ischemic cells, but not intact or infarcted cells. ${ }^{12}$ Therefore, this indicated a sustained ischemia lasting for at least 16 days. In similar canine experiments, ${ }^{9,10}$ substantial NADH fluorescence was noted 2 months after microsphere injection into the coronary arteries.

Forty minutes after completion of the indium-labeled microsphere injection, adenovirus-containing saline solution $(2 \mathrm{~mL})$ or pure saline solution $(2 \mathrm{~mL})$ was injected into 39 animals in the same manner as in the indium-labeled microspheres. Ten minutes before (baseline) injection of the indium-labeled microspheres, and 10 minutes after (acute phase), barium- and iodine-labeled microspheres $\left(1.25 \times 10^{5} / \mathrm{kg}\right)$, respectively, were injected without balloon inflation to measure blood flow in the major organs. Twodimensional and M-mode echocardiographic images (SSD630; Aloka Co, Ltd, Mitaka, Japan) were obtained via a right parasternal approach to determine the ejection fraction. Cerium-labeled microsphere injection to measure regional blood flow and echocardiographic measurements were repeated $17 \pm 3$ days after induction of ischemia (chronic phase). After the animals had been killed, their major organs were dissected out, and the x-ray fluorescence of each heavy element was measured to calculate regional blood flow. ${ }^{11}$ Lactate content in the left ventricle was also evaluated after the myocardium was frozen quickly with liquid nitrogen. ${ }^{13}$ Arteriolar density was evaluated 
as the number of intramyocardial arterioles in the left ventricle ${ }^{14,15}$ (the free wall and the interventricular septum) by blinded analysis (alkaline phosphatase staining). ${ }^{16}$ Two investigators blinded to treatment graded histologic evidence of infarction in each tissue section stained with azan and hematoxylin-eosin on a scale of 0 to 3 as follows: $0=$ none; $1=$ mild (less than $5 \%$ of the section surface); $2=$ moderate (more than $5 \%$, up to $20 \%$ of the section surface); and $3=$ severe (more than $20 \%$ of the section surface). Expression of lacZ was determined 4 days after transfection by X-Gal histologic staining as previously reported ${ }^{17}$ in 2 rabbits in the sham-2 group. VEGF expression was quantified 4 days after transfection with the Quantikine human VEGF immunoassay (R\&D Systems, Inc, Minneapolis, Minn) in 8 rabbits in the sham-1 $(n=4)$ and VEGF groups $(\mathrm{n}=4)$. Tissue samples $(0.5 \mathrm{~g})$ were homogenized and protein determinations were performed in duplicate according to the methods of Magovern and associates. ${ }^{18}$ The standard wells against which the samples were compared contained equal amounts of normal rabbit tissue homogenate to correct for any background that might interfere with the absorbance. ${ }^{19}$ The concentration of VEGF was normalized to milligrams of protein.

Coronary angiography. In 6 ischemic rabbits $(3$ in the sham- 1 group and 3 in the VEGF group), synchrotron radiation angiography was performed as previously described. ${ }^{20,21}$ In brief, monochromatic synchrotron radiation with an energy level of $33.3 \mathrm{keV}$ was used as the $\mathrm{x}$-ray source, and contrast images of the object were formed on a high-sensitivity fluorescent screen (FOS; Hamamatsu Photonics Co, Hamamatsu, Japan), which was scanned at 30 frames/s by a high-definition television camera with 1125 television lines (New Super HARP; NHK, Tokyo, Japan). This system is capable of separating adjacent lead lines only $25 \mu \mathrm{m}$ apart on the resolution bar chart. Sixteen or 17 days after induction of ischemia, a 4F catheter was placed near the aortic valve in the ascending aorta via the left carotid artery, and contrast material containing $37 \%$ nonionic iodine (iopamidol; Nihon Schering Co Ltd, Tokyo, Japan) was injected. Morphometric angiographic analysis of collateral vessel development was performed as previously described. ${ }^{21}$ In brief, a composite of $0.5 \times 0.5 \mathrm{~mm}$ grids was placed over the thigh area of the angiogram. The total number of grid intersections and the total number of intersections crossed by a contrast-opacified artery were counted individually by a single observer blinded to the treatment regimen. An angiographic score was calculated for each animal as the ratio of grid intersections crossed by opacified arteries divided by the total number of grid intersections.

Recombinant adenoviral vectors. Replication-defective E1 and E3 adenoviral vectors expressing either human VEGF $_{165}{ }^{22}$ (Ad-VEGF) or $\beta$-galactosidase (Ad-lacZ) under a CA promoter comprising a cytomegalovirus enhancer and chicken $\beta$-actin promoter ${ }^{23}$ were prepared by in vitro homologous recombination in a 293-cell assay system, as previously described. ${ }^{17,24}$ The desired recombinant adenovirus was purified by ultracentrifugation through a $\mathrm{CsCl}_{2}$ gradient followed by extensive dialysis. Contamination of wild-type ade- novirus was excluded by polymerase chain reaction designed for E1 amplification. ${ }^{17}$ The titer of the virus stock was assessed by a plaque-formation assay with the 293-cell system and expressed as plaque-forming units. ${ }^{24}$

Statistical analysis. Data are presented as mean values \pm SD. Differences between means were assessed by the paired $t$ test, Wilcoxon signed rank sum test, Mann-Whitney test, or analysis of variance for factorial or repeated measures with the Scheffé F test when applicable.

\section{Results}

Functional effects of intracoronary injection of microspheres in the acute phase (data from the 3 groups). Microsphere injection reduced myocardial perfusion $(78 \% \pm 9 \%$ of baseline tissue flow), diminished myocardial contraction $(61 \% \pm 12 \%$ of the baseline ejection fraction), and cardiac performance (elevated left ventricular end-diastolic pressure [LVEDP] and decreased systemic flow [renal and cerebral flow]) in the acute phase. The absolute values of these indices in each group are shown in the baseline and acute phase lines in Table I, and they were not significantly different among the 3 groups.

Amelioration of myocardial ischemia with AdVEGF. After $17 \pm 2$ days, intracoronary injection of Ad-VEGF had promoted coronary angiogenesis as evidenced by myocardial flow above the baseline, increased vascular density as observed by microangiography and histologic analysis, ameliorated the degree of myocardial ischemia as evidenced by myocardial lactate content and the extent of histologic necrosis, and restored heart function as evidenced by LVEDP reduction, increased ejection fraction, and body weight restoration. These indices are summarized in Table I.

Ad-VEGF promoted angiogenesis in the myocardium, as indicated by the regional blood flow measurements, microangiograms, and histologic analysis (ANOVA). In the chronic phase (17 days after induction of ischemia), myocardial blood flow surpassed its baseline value $(121 \% \pm 24 \%)$ in the VEGF group but was not restored to the baseline $(92 \% \pm 14 \%$ and $87 \% \pm 15 \%)$ in the sham groups. The absolute myocardial flow value in the VEGF group $\left(2.95 \pm 0.23 \mathrm{~mL} \cdot \mathrm{min}^{-1} \cdot \mathrm{g}^{-1}\right)$ significantly exceeded the values in the 2 sham groups $(2.22 \pm 0.42$ and 2.24 $\pm 0.23 \mathrm{~mL} \cdot \mathrm{min}^{-1} \cdot \mathrm{g}^{-1}, P<.05$, ANOVA). Synchrotron radiation coronary microangiography showed that the peripheral coronary arteries (90-510 $\mu \mathrm{m}$ in diameter) became more prominent in the VEGF gene-treated rabbits than in the sham rabbits and that localized dense contrast regions were occasionally noted in the former (Fig 1). These changes are probably due to enhancement of regional blood flow evoked by the angiogenic action of 
Table I. Effects of intracoronary injection of microspheres and recombinant adenovirus expressing lacZ and $V E F G_{165}$

\begin{tabular}{|c|c|c|c|c|c|}
\hline & & \multirow[b]{2}{*}{$\begin{array}{l}\text { Normal standard rabbits } \\
\qquad(n=7)\end{array}$} & \multicolumn{3}{|c|}{ Ischemic rabbits $(n=29)$} \\
\hline & & & $\begin{array}{l}\text { Sham-1 } \\
(n=14)\end{array}$ & $\begin{array}{l}\text { Sham-2 } \\
(n=6)\end{array}$ & $\begin{array}{l}V E G F \\
(n=9)\end{array}$ \\
\hline Chronic phase (d) & & $16.9 \pm 2.3(7)$ & $16.9 \pm 4.4(11)$ & $16.7 \pm 2.9(6)$ & $16.8 \pm 2.1(6)$ \\
\hline \multicolumn{6}{|l|}{ Myocardial circulation } \\
\hline \multicolumn{6}{|l|}{ Myocardial blood flow } \\
\hline \multirow{3}{*}{$\left(\mathrm{mL} \cdot \mathrm{min}^{-1} \cdot \mathrm{g}^{-1}\right)$} & Acute phase & & $1.94 \pm 0.44 *$ & $2.00 \pm 0.30^{*}$ & $1.87 \pm 0.26^{*}$ \\
\hline & Chronic phase & & $2.22 \pm 0.42$ & $2.24 \pm 0.23^{*}$ & $2.95 \pm 0.23^{* \dagger} \S$ \\
\hline & Percent change & & $92 \% \pm 14 \%$ & $87 \% \pm 15 \%$ & $121 \% \pm 24 \% \S$ \\
\hline \multicolumn{6}{|l|}{ Arteriolar density } \\
\hline Angiographic score & Chronic phase & & $0.55 \pm 0.07$ & & $0.76 \pm 0.05(3) \S$ \\
\hline \multicolumn{6}{|l|}{ Myocardial metabolism } \\
\hline Lactate content $(\mathrm{mg} / \mathrm{g})$ & Chronic phase & $0.58 \pm 0.06(7)$ & $1.27 \pm 0.72(7) 末$ & $1.19 \pm 0.28(6)^{\ddagger}$ & $0.67 \pm 0.13(5) \S$ \\
\hline \multicolumn{6}{|l|}{ Heart function } \\
\hline \multirow[t]{4}{*}{ Ejection fraction (\%) } & Baseline & & $68 \pm 6(11)$ & $70 \pm 3(6)$ & $69 \pm 6(6)$ \\
\hline & Acute phase & & $45 \pm 6^{*}$ & $43 \pm 8^{*}$ & $37 \pm 8^{*}$ \\
\hline & Chronic phase & & $49 \pm 6^{*}$ & $42 \pm 12 *$ & $65 \pm 8 \dagger \S$ \\
\hline & Percent change & & $71 \% \pm 9 \%$ & $59 \% \pm 16 \%$ & $95 \% \pm 10 \% \S$ \\
\hline \multirow[t]{4}{*}{ LVEDP (mm Hg) } & Baseline & & $5.5 \pm 4.8(11)$ & $8.8 \pm 2.8(6)$ & $9.8 \pm 2.9(6)$ \\
\hline & Acute phase & & $8.2 \pm 4.0$ & $13.5 \pm 6.9$ & $13.2 \pm 4.5$ \\
\hline & Chronic phase & & $13.0 \pm 5.4^{*} \dagger$ & $17.7 \pm 11.6$ & $7.2 \pm 4.6$ \\
\hline & $\Delta$ change & & $7.5 \pm 6.8$ & $8.8 \pm 12.6$ & $-2.8 \pm 4.4 \S$ \\
\hline \multicolumn{6}{|l|}{ Mean aortic pressure } \\
\hline \multirow[t]{3}{*}{$(\mathrm{mm} \mathrm{Hg})$} & Baseline & & $112 \pm 8(11)$ & $109 \pm 7(6)$ & $115 \pm 9(6)$ \\
\hline & Acute phase & & $99 \pm 11$ & $95 \pm 8$ & $102 \pm 9$ \\
\hline & Chronic phase & & $117 \pm 23 \dagger$ & $112 \pm 20$ & $102 \pm 18$ \\
\hline \multirow[t]{3}{*}{ Heart rate (beats/min) } & Baseline & & $243 \pm 48(11)$ & $252 \pm 42(6)$ & $232 \pm 29(6)$ \\
\hline & Acute phase & & $226 \pm 42$ & $228 \pm 27$ & $213 \pm 41$ \\
\hline & Chronic phase & & $260 \pm 27$ & $275 \pm 41$ & $267 \pm 44 \dagger$ \\
\hline \multicolumn{6}{|l|}{ Systemic indices } \\
\hline \multirow[t]{3}{*}{ Body weight (kg) } & Baseline & $3.43 \pm 0.31(7)$ & $3.71 \pm 0.19$ & $3.49 \pm 0.31(6)$ & $3.68 \pm 0.28(6)$ \\
\hline & Chronic phase & $3.63 \pm 0.32 *$ & $3.40 \pm 0.26^{*}$ & $3.20 \pm 0.28 \pi$ & $3.73 \pm 0.27 \S$ \\
\hline & Percent change & $106 \% \pm 2 \%$ & $92 \% \pm 8 \% \ddagger$ & $92 \% \pm 7 \% 末$ & $102 \% \pm 4 \% \S$ \\
\hline \multirow{5}{*}{$\begin{array}{l}\text { Renal blood flow } \\
\qquad\left(\mathrm{mL} \cdot \mathrm{min}^{-1} \cdot \mathrm{g}^{-1}\right)\end{array}$} & & & & & \\
\hline & Baseline & & $4.55 \pm 1.11(11)$ & $3.96 \pm 0.71(6)$ & $3.97 \pm 0.63(6)$ \\
\hline & Acute phase & & $3.86 \pm 1.03$ & $3.22 \pm 0.42$ & $3.27 \pm 0.49$ \\
\hline & Chronic phase & & $2.85 \pm 0.45^{*} \dagger$ & $3.10 \pm 0.51$ & $2.71 \pm 0.64^{*}$ \\
\hline & Percent change & & $68 \% \pm 30 \%$ & $80 \% \pm 18 \%$ & $70 \% \pm 21 \%$ \\
\hline \multirow{5}{*}{$\begin{array}{l}\text { Cerebral blood flow } \\
\qquad\left(\mathrm{mL} \cdot \mathrm{min}^{-1} \cdot \mathrm{g}^{-1}\right)\end{array}$} & & & & & \\
\hline & Baseline & & $0.62 \pm 0.16$ & $0.53 \pm 0.10(6)$ & $0.68 \pm 0.09(6)$ \\
\hline & Acute phase & & $0.44 \pm 0.16^{*}$ & $0.38 \pm 0.07$ & $0.46 \pm 0.08^{*}$ \\
\hline & Chronic phase & & $0.56 \pm 0.18 \dagger$ & $0.45 \pm 0.14$ & $0.57 \pm 0.15$ \\
\hline & Percent change & & $93 \% \pm 28 \%$ & $86 \% \pm 25 \%$ & $84 \% \pm 22 \%$ \\
\hline
\end{tabular}

The coronary arteries of all rabbits were injected with $15-\mu \mathrm{m}$ microspheres to induce myocardial ischemia. Saline solution, Ad-lacZ, or Ad-VEGF was injected into the coronary artery after the microsphere injection (sham-1, sham-2, and VEGF group, respectively). The above-described indices were measured immediately before, immediately after, and 17 days after injection of the microspheres (baseline, acute phase, and chronic phase, respectively); Percent change, (Chronic phase/baseline) $\times 100 ; \Delta$ change, Chronic phase - Baseline. The numbers of animals are indicated in parentheses. LVEDP, Left ventricular end-diastolic pressure. Data are means \pm SD. $P<.05$ versus baseline* and acute phase $\dagger$ (ANOVA for repeated measures with the Scheffé F test) and versus normal standard, $\$$ sham- $1, \S$ and sham-2 groups $\|$ (ANOVA for factorial with the Scheffé $\mathrm{F}$ test). $\llbracket[P=.053$ versus baseline (paired $t$ test).

the transferred VEGF gene. Histologic examination demonstrated other evidence of enhanced angiogenesis in the VEGF group. The number of intramyocardial arterioles $(20-100 \mu \mathrm{m}$ in diameter) was increased approximately 2 -fold by Ad-VEGF treatment $(P<.05$, ANOVA, Table I, Fig 2, $A$ and $B$ ).
Metabolic evaluation and histologic analysis revealed that Ad-VEGF ameliorated the degree of myocardial ischemia. The myocardial lactate content in the VEGF group was restored to a level similar to the normal standard by the end of the experiment, and the levels in these 2 groups were significantly lower than in the 2 


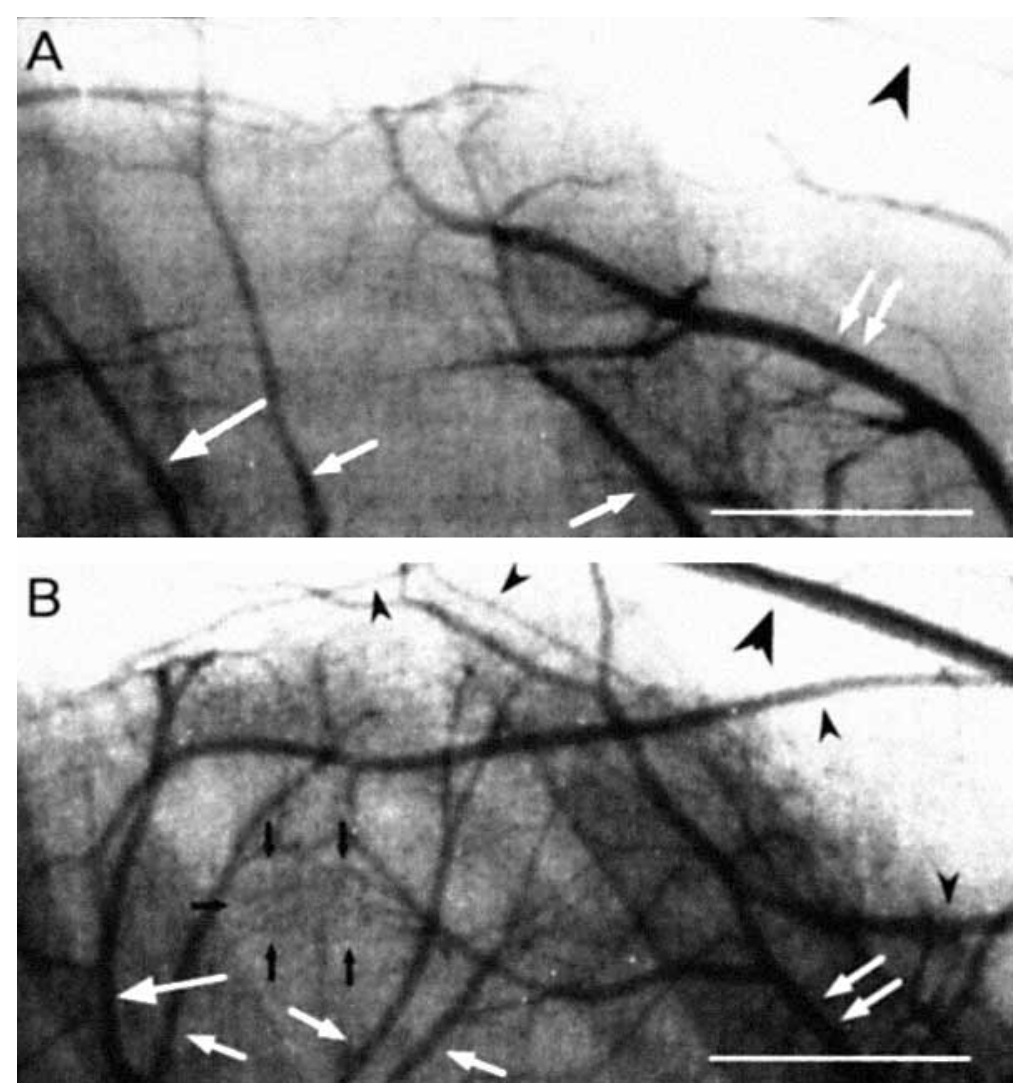

Fig 1. Angiograms of the ischemic heart. Contrast material was injected into the ascending aorta 16 days after induction of ischemia. Opacified vessels around the apex are shown in the rabbits in the sham-1 group (A) and VEGF group (B). The large and medium white arrows point to the peripheral portion of the left circumflex artery and its first-order branches, respectively; the double white arrows to the peripheral portion of the left anterior descending artery; the small black arrows to localized dense contrast region; and the large and small arrowheads to the internal thoracic artery and its branches, respectively. Bar $=5 \mathrm{~mm}$.

sham groups $(P<.05$, ANOVA, Table I). Histologic analysis revealed multiple, small patchy infarctions with inflammatory infiltrates surrounded by noninfarcted myocardium throughout the heart, but the extent of the infarctions in the VEGF group was smaller than in the sham groups $(P=.02$, Mann-Whitney test, Fig 2, $C$ and $D$ ). In the sham control rabbits, the left side of the interventricular septum exposed to the high-pressure chamber showed more marked infarction than the right side, and the infarction area determined semiquantitatively was more marked in the subendocardial region of the left ventricular free wall than in the subepicardial muscle $(P=.01$, Wilcoxon signed rank sum test, Fig 2, C).

Treatment with Ad-VEGF restored heart function. In the chronic phase, the ejection fraction in the VEGF group was restored to a sub-baseline value $(95 \% \pm 10 \%$ of the baseline value), whereas in sham groups it remained similar to the levels in the acute phase $(P<$
.05, ANOVA, Table I). LVEDP decreased within 17 days in the VEGF group but did not improve in the sham groups. The degree of LVEDP recovery (chronic phase value minus baseline value) was greater in the VEGF group than in the sham groups $(P<.05$, ANOVA, Table I).

Assessment of systemic functions showed that treatment with Ad-VEGF partially prevented the body weight loss caused by inducing ischemia. Four of the 6 rabbits in the VEGF group gained weight as did the normal standard rabbits, whereas all animals in the sham groups lost weight during the 17 days $(P<.05$, ANOVA, Table I). Abnormal signs of increased vascular permeability, such as tissue edema and ascites, were not observed in VEGF-treated rabbits. Cerebral blood flow recovered to sub-baseline values, but the recovery in renal blood flow was not enough in all 3 groups in the chronic phase. No significant effect of Ad-VEGF was seen in these 2 systemic perfusion indices. No his- 
tologic evidence of ischemia or pathologic changes, including inflammation, was found in other major organs (brain, kidney, and liver) in any of the groups. No clear differences in any of the indices or morphologic findings were seen between the sham- 1 and sham-2 groups.

Gene expression in vivo. Tissue levels of VEGF were $44 \pm 28 \mathrm{pg} / \mathrm{mg}$ protein in the heart and were below the detection limit (5 pg/mg) in the brain, kidney, and plasma in Ad-VEGF-treated animals 4 days after the intracoronary injection $(P<.05$, heart vs brain, kidney, and plasma, ANOVA, $\mathrm{n}=4)$. In the sham-1 group $(\mathrm{n}=$ 4), VEGF levels in the heart were $7 \pm 9 \mathrm{pg} / \mathrm{mg}(P=.04$ vs VEGF group, unpaired $t$ test), and those in the other 3 tissues were less than $5 \mathrm{pg} / \mathrm{mg}$. The expression of lacZ was confirmed in the vascular cell and the surrounding tissue in the heart by X-Gal histostaining 4 days after the injection in the sham-2 group $(\mathrm{n}=2$, data not shown).

\section{Discussion}

New findings in this study. In vivo gene transfer by means of recombinant Ad-VEGF was an effective approach to the treatment of microvascular ischemia. When the animals were examined $17 \pm 3$ days later, semi-selective injection of Ad-VEGF into the coronary artery after induction of ischemia promoted coronary angiogenesis (Table I, Fig 1, and Fig 2, $A$ and $B$ ), ameliorated the degree of myocardial ischemia (Table I and Fig 2, $C$ and $D$ ), and restored heart function (Table I).

Considerations in regard to the experimental model. Chilian and colleagues ${ }^{25}$ reported that injection of a certain number of microspheres $(25 \mu \mathrm{m}$ in diameter, $2 \times 10^{5} / \mathrm{g}$ myocardium) into the left circumflex artery abolished coronary vasodilator reserve but maintained blood flow at rest in dogs. Under these conditions, myocardial oxygen supply and demand is unbalanced except at rest. In our model, the calculated number of microspheres was approximately 55\% $\left(1.1 \times 10^{5} / \mathrm{g}\right.$ myocardium $)$ and their diameter was smaller $(15 \mu \mathrm{m})$, but the whole heart was involved. The results in the preliminary study (paragraph 4 in the "Methods" section) validated that our model is a delayed infarction model rather than an acute infarction model. Histologic studies showed that small patchy infarctions extended over all segments of the heart but occurred predominantly in the inner region of the left ventricle and that a large portion of the myocardium was not necrotic (Fig 2,C). Because the microspheres were injected while blood flow into the descending aorta and bilateral carotid arteries was stopped, precapillary arteriole plugging by microspheres occurred semi-selectively in the heart, but not in other tissues, except for the area perfused by the subclavian arteries. The microsphere plugging of the coronary arterial system induced microvascular myocardial ischemia. The increased LVEDP, decreased ejection fraction, and decreased body weight constituted evidence of myocardial dysfunction. The $87 \%$ to $92 \%$ recovery of "mean" myocardial flow does not always indicate substantial recovery in myocardial perfusion and heart function.

In our recent experiments using microsphere plugging in dogs, ${ }^{9,10}$ regional ischemic myocardial flow was characterized by its large variability (analyzed with synchrotron radiation: resolution 2-3 $\mathrm{mg}^{26}$ ) but "mean" flow in the ischemic region was not different from that in the normal region (analyzed with conventional x-ray techniques: resolution 2-3 g). Furthermore, this variability in flow was associated with contractile deterioration and high tissue lactate content; that is, the microsphere-plugging model produces substantial disparity in flow distribution in milligram-order flow analysis that cannot be detected by gram-order flow analysis. In other words, small number of regions with a markedly increased flow increased the mean value, but substantial regions were still in the critical flow range. Thus, the possibility that some regions with markedly decreased flow decreased the mean value in the acute phase cannot be ruled out. However, the contraction was worst in the acute phase.

The effects of angiogenic therapy have been reported in several animal models in which myocardial ischemia was induced by occluding the proximal left circumflex artery with an ameroid constrictor. ${ }^{3,4,6,7}$ The advantage of using the ameroid constrictor is that myocardial ischemia develops gradually and resembles the most common type of coronary artery disease seen in clinical settings. Ischemia induced with an ameroid constrictor involves proximal segments of major coronary artery branches; in contrast, our model involves multiple peripheral coronary segments.

Amelioration of myocardial ischemia with AdVEGF. The results of the present study clearly showed that gene transfer of $\mathrm{VEGF}_{165}$ with an adenoviral vector increased myocardial VEGF level and improved myocardial blood flow and intramyocardial vessel density. These results are evidence of promotion of angiogenesis by Ad-VEGF. The increased intramyocardial arterial (90-510 $\mu \mathrm{m}$ in diameter) and arteriolar (20-100 $\mu \mathrm{m}$ in diameter) density may, at least in part, be due to a remodeling of smaller vessels, because the period for examining the effect of Ad-VEGF (17 \pm 3 days) was obviously too short for new large vessels to form. Therefore, the angiogenesis induced by injecting AdVEGF into the ischemic heart in vivo in the present 


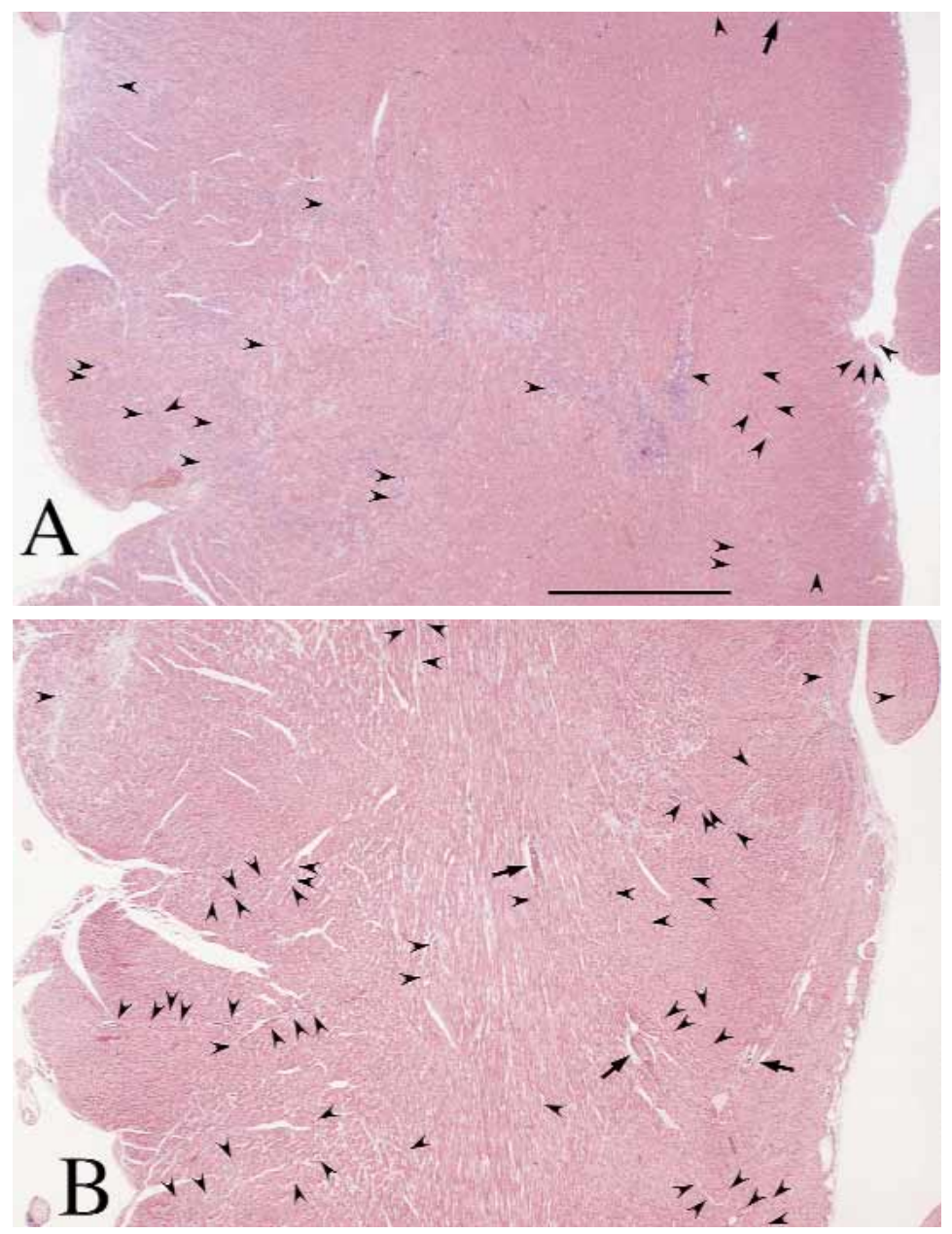

Fig 2. Histologic examination of myocardium with microvascular ischemia in the rabbit. $\mathbf{A}$ and $\mathbf{C}$, Sixteen days after intracoronary injection of microspheres (sham-1 group). The infarction scores of the left and right sides of the interventricular septum (IVS) are 3 and 2, respectively. $\mathbf{B}$ and $\mathbf{D}$, Sixteen days after injection of microspheres and Ad-VEGF (VEGF group). The infarction scores on both sides of the interventricular septum are 1. Arrowheads, Intramyocardial arterioles (20-100 $\mu \mathrm{m}$ in diameter); arrows, arteries with a diameter of more than $100 \mu \mathrm{m} ; L V C$, left ventricular cavity; $R V C$, right ventricular cavity. Hematoxylin and eosin stain (A and $\mathbf{B})$; azan stain $(\mathbf{C}$ and $\mathbf{D})$. Original magnifications $\times 6.1$; bar $=1 \mathrm{~mm}$.

experiments was a primary event. A similar reaction was observed around the internal thoracic artery (Fig 1, $B)$. This is due to "semi-selective" injection in which both indium-labeled microspheres and adenovirus were delivered to this artery via uninterrupted subclavian arteries, as well as to the coronary arteries.

The angiogenesis induced by Ad-VEGF ameliorated the degree of myocardial ischemia. The reduction of lactate content and necrotic area in the myocardium was related to the improvement of regional perfusion, that is, the angiogenesis in the myocardium. Amelioration of myocardial ischemia restored heart function to a certain extent (reduction in LVEDP and increase in ejection fraction). However, recovery in systemic perfusion, such as cerebral and renal blood flow, was not enough. As shown in Table I, the VEGF group is characterized by reduced LVEDP $(7.2 \mathrm{~mm} \mathrm{Hg}$ in mean, $73 \%$ of baseline) and slightly decreased renal flow ( $70 \%$ of baseline). Relative cardiac output arbitrarily determined by percent change of renal flow divided by percent change of LVEDP was 0.96 $(70 \% / 73 \%)$. These indices in the sham-1 (0.29) and sham-2 groups (0.40) were obviously lower than the VEGF value. Capillary leak induced by VEGF might be related in part to reduction in preload. The reduction in preload may have unloaded the ventricle and result- 


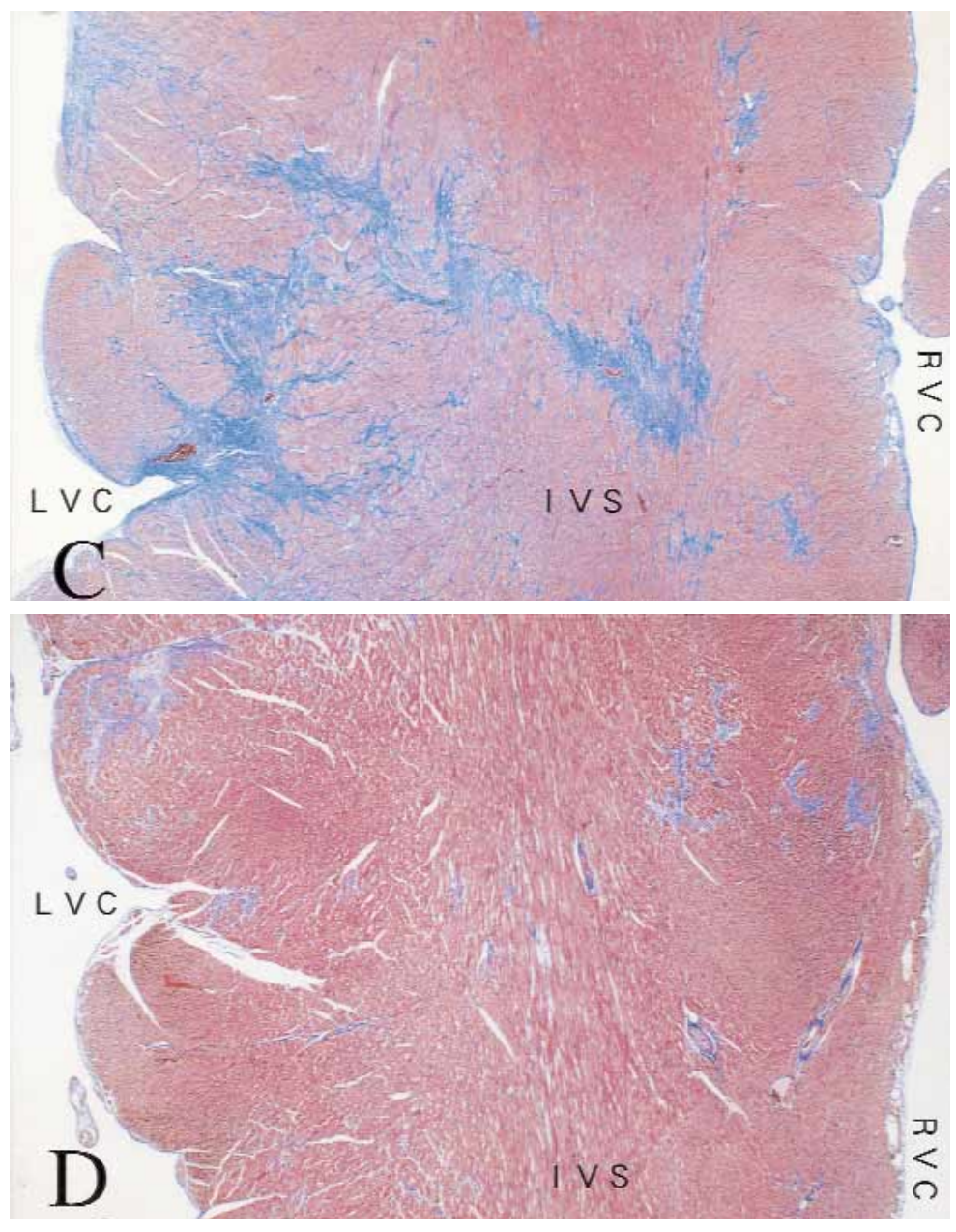

Fig 2. Cont'd.

ed in improvement in ejection fraction. The lack of efficacy of Ad-lacZ on ischemia demonstrated that the angiogenesis was due to the gene transfer of $\mathrm{VEGF}_{165}$, not the vector.

On day 4 after the intracoronary injection of AdVEGF, expression of VEGF gene was confirmed in the heart by the analysis of tissue VEGF levels but not in the periphery, namely, the brain, kidney, and plasma. LacZ study also confirmed the gene expression in the heart (data not shown). Since expression of the transfected VEGF gene is limited to 2 to 3 weeks, ${ }^{27}$ we killed the animals 14 to 21 days (mean 17 days) after gene transfer. An acute inflammatory reaction has been reported $^{28,29}$ to be a drawback to the use of adenoviral vectors. In our model, inflammatory changes were observed only in the heart but not in the brain, kidney, or liver. We could not distinguish the adenoviral inflammation from the reaction to infarction. However, the degree of inflammatory reactions in the sham-2 group was similar to that in the sham-1 group (relatively moderate), and those in the VEGF group were less severe. These results suggest that adenoviral vectors were unlikely to be a main cause for inflammatory changes in the heart. In addition, we could not find tissue edema or ascites due to increased vascular permeability.

In summary, the present results indicate that in vivo gene transfer of $\mathrm{VEGF}_{165}$ can be used to treat microvascular myocardial ischemia that is unresponsive to conventional therapies such as percutaneous transluminal coronary angioplasty or coronary artery bypass grafting.

We thank Drs Masabumi Shibuya, Norikazu Tamaoki, Masato Nakamura, Satoshi Takeshita, Motoaki Sano, Yoshiro Shinozaki, Satoshi Hamanoue, Kaori Suyama, and Ayako Nishizawa for comments; we thank Dr Izumu Saito 
(University of Tokyo) and Dr Junichi Miyazaki (Tohoku University) for a cosmid vector (for preparation of recombinant adenoviruses).

\section{REFERENCES}

1. Ferrara N, Houck K, Jakeman L, Leung DW. Molecular and biological properties of the vascular endothelial growth factor family of proteins. Endocr Rev 1992;13:18-32.

2. Shibuya M. Role of VEGF-flt receptor system in normal and tumor angiogenesis. Adv Cancer Res 1995;67:281-316.

3. Banai S, Jaklitsch MT, Shou M, Lazarous DF, Scheinowitz M, Biro S, et al. Angiogenic-induced enhancement of collateral blood flow to ischemic myocardium by vascular endothelial growth factor in dogs. Circulation 1994;89:2183-9.

4. Harada K, Friedman M, Lopez JJ, Wang SY, Li J, Prasad PV, et al. Vascular endothelial growth factor administration in chronic myocardial ischemia. Am J Physiol 1996;270:H1791-802.

5. Kass EA, Falck PE, Alvira M, Rivera J, Buttrick PM, Wittenberg BA, et al. Quantitative determination of adenovirus-mediated gene delivery to rat cardiac myocytes in vitro and in vivo. Proc Natl Acad Sci U S A 1993;90:11498-502.

6. Mack CA, Patel SR, Schwarz EA, Zanzonico P, Hahn RT, Ilercil $\mathrm{A}$, et al. Biologic bypass with the use of adenovirus-mediated gene transfer of the complementary deoxyribonucleic acid for vascular endothelial growth factor121 improves myocardial perfusion and function in the ischemic porcine heart. J Thorac Cardiovasc Surg 1998;115:168-76.

7. Giordano FJ, Ping P, McKirnan MD, Nozaki S, DeMaria AN, Dillmann WH, et al. Intracoronary gene transfer of fibroblast growth factor-5 increases blood flow and contractile function in an ischemic region of the heart. Nat Med 1996;2:534-9.

8. Likoff W, Segal BL, Kasparian H. Paradox of normal selective coronary arteriograms in patients considered to have unmistakable coronary heart disease. N Engl J Med 1967;276:1063-6.

9. Ban K, Hattan N, Abe S, Tanaka E, Suyama K, Shinozaki Y, et al. Development of peripherally distributed myocardial ischemia in chronic canine model [abstract]. J Mol Cell Cardiol 1998;30:A22.

10. Ban K, Mori H, Hattan N. The effects of TMR on microvascular myocardial ischemia. J Board Certif Mem Jpn Circ Soc 1999;7:301-6 (in Japanese).

11. Tanaka E, Mori H, Chujo M, Yamakawa A, Mohammed MU, Shinozaki Y, et al. Coronary vasoconstrictive effects of neuropeptide $\mathrm{Y}$ and their modulation by the ATP-sensitive potassium channel in anesthetized dogs. J Am Coll Cardiol 1997;29:1380-9.

12. Hori S, Nakazawa H, Ohnishi Y, Yoshino H, Murayama A, Nishikawa Y, et al. A rapid cross-sectioning and freeze-clamping device for the beating canine heart. J Mol Cell Cardiol 1989;21:203-10.

13. Mori H, Nagata M, Miyazaki T, Sakurai K, Ogawa S, Hattori S, et al. Protection of hypoxic myocardium by intracoronary administration of verapamil in open-chest dogs. Circulation 1984;70:742-7.

14. Kohmoto T, DeRosa CM, Yamamoto N, Fisher PE, Failey P, Smith CR, et al. Evidence of vascular growth associated with laser treatment of normal canine myocardium. Ann Thorac Surg 1998;65:1360-7.
15. Kurosawa S, Kurosawa H, Becker AE. The coronary arterioles in newborns, infants and children: a morphometric study of normal hearts and hearts with aortic atresia and complete transposition. Int J Cardiol 1986;10:43-56.

16. Takeshita S, Zheng LP, Brogi E, Kearney M, Pu LQ, Bunting S, et al. Therapeutic angiogenesis: a single intraarterial bolus of vascular endothelial growth factor augments revascularization in a rabbit ischemic hind limb model. J Clin Invest 1994;93:662-70.

17. Ueno H, Li JJ, Tomita H, Yamamoto H, Pan Y, Kanegae Y, et al. Quantitative analysis of repeat adenovirus-mediated gene transfer into injured canine femoral arteries. Arterioscler Thromb Vasc Biol 1995; 15:2246-53.

18. Magovern CJ, Mack CA, Zhang J, Hahn RT, Ko W, Isom OW, et al. Direct in vivo gene transfer to canine myocardium using a replication-deficient adenovirus vector. Ann Thorac Surg 1996;62:425-33.

19. Lee LY, Patel SR, Hackett NR, Mack CA, Polce DR, El ST, et al. Focal angiogen therapy using intramyocardial delivery of an adenovirus vector coding for vascular endothelial growth factor 121 . Ann Thorac Surg 2000;69:14-23.

20. Mori H, Hyodo K, Tanaka E, Mohammed MU, Yamakawa A, Shinozaki Y, et al. Small-vessel radiography in situ with monochromatic synchrotron radiation. Radiology 1996;201:173-7.

21. Takeshita S, Isshiki T, Mori H, Tanaka E, Tanaka A, Umetani K, et al. Microangiographic assessment of collateral vessel formation following direct gene transfer of vascular endothelial growth factor in rats. Cardiovasc Res 1997;35:547-52.

22. Sawano A, Takahashi T, Yamaguchi S, Aonuma M, Shibuya M. Flt-1 but not KDR/Flk-1 tyrosine kinase is a receptor for placenta growth factor, which is related to vascular endothelial growth factor. Cell Growth Differ 1996;7:213-21.

23. Niwa H, Yamamura K, Miyazaki J. Efficient selection for highexpression transfectants with a novel eukaryotic vector. Gene 1991;108:193-9.

24. Yamamoto H, Ueno H, Ooshima A, Takeshita A. Adenovirusmediated transfer of a truncated transforming growth factor-beta (TGF-beta) type II receptor completely and specifically abolishes diverse signaling by TGF-beta in vascular wall cells in primary culture. J Biol Chem 1996;271:16253-9.

25. Chilian WM, Mass HJ, Williams SE, Layne SM, Smith EE, Scheel KW. Microvascular occlusions promote coronary collateral growth. Am J Physiol 1990;258:H1103-11.

26. Mori H, Chujo M, Haruyama S, Sakamoto H, Shinozaki Y, Uddin MM, et al. Local continuity of myocardial blood flow studied by monochromatic synchrotron radiation-excited $\mathrm{x}$-ray fluorescence spectrometry. Circ Res 1995;76:1088-100.

27. Tsurumi Y, Takeshita S, Chen D, Kearney M, Rossow ST, Passeri $\mathrm{J}$, et al. Direct intramuscular gene transfer of naked DNA encoding vascular endothelial growth factor augments collateral development and tissue perfusion. Circulation 1996;94:3281-90.

28. Schulick AH, Newman KD, Virmani R, Dichek DA. In vivo gene transfer into injured carotid arteries: optimization and evaluation of acute toxicity. Circulation 1995;91:2407-14.

29. Feldman LJ, Pastore CJ, Aubailly N, Kearney M, Chen D, Perricaudet M, et al. Improved efficiency of arterial gene transfer by use of poloxamer 407 as a vehicle for adenoviral vectors. Gene Ther 1997;4:189-98. 